\title{
Efficacy of condensed tannins against larval Hymenolepis diminuta (Cestoda) in vitro and in the intermediate host Tenebrio molitor (Coleoptera) in vivo
}

Article

Accepted Version

Dhakal, S., Meyling, N. V., Williams, A. R., Mueller-Harvey, I., Fryganas, C., Kapel, C. M.O. and Fredensborg, B. L. (2015) Efficacy of condensed tannins against larval Hymenolepis diminuta (Cestoda) in vitro and in the intermediate host Tenebrio molitor (Coleoptera) in vivo. Veterinary Parasitology, 207 (1-2). pp. 49-55. ISSN 03044017 doi: https://doi.org/10.1016/j.vetpar.2014.11.006 Available at https://centaur.reading.ac.uk/38468/

It is advisable to refer to the publisher's version if you intend to cite from the work. See Guidance on citing.

Published version at: http://dx.doi.org/10.1016/j.vetpar.2014.11.006

To link to this article DOI: http://dx.doi.org/10.1016/j.vetpar.2014.11.006

Publisher: Elsevier

All outputs in CentAUR are protected by Intellectual Property Rights law, including copyright law. Copyright and IPR is retained by the creators or other copyright holders. Terms and conditions for use of this material are defined in the End User Agreement. 


\section{www.reading.ac.uk/centaur}

\section{CentAUR}

Central Archive at the University of Reading

Reading's research outputs online 

vitro and in the intermediate host Tenebrio molitor (Coleoptera) in vivo Suraj Dhakal ${ }^{\mathrm{a}}$, Nicolai V. Meyling ${ }^{\mathrm{a}}$, Andrew R. Williams ${ }^{\mathrm{b}}$, Irene Mueller-Harvey ${ }^{\mathrm{c}}$, Christos Fryganas ${ }^{\mathrm{c}}$, Christian M. O. Kapel ${ }^{\mathrm{a}}$, Brian L. Fredensborg ${ }^{\mathrm{a} *}$

${ }^{a}$ Department of Plant and Environmental Sciences, Faculty of Science, University of Copenhagen, Frederiksberg C, Denmark.

${ }^{b}$ Department of Veterinary Disease Biology, Faculty of Health and Medical Sciences, University of Copenhagen, Frederiksberg C, Denmark.

${ }^{c}$ Chemistry and Biochemistry Laboratory, School of Agriculture, Policy and Development, University of Reading, Reading, United Kingdom.

* Corresponding author at: Department of Plant and Environmental Sciences, Faculty of Science, University of Copenhagen, Thorvaldsensvej 40, Room 70-3-B324, Frederiksberg C, Copenhagen, Denmark. Tel.: +45 353326 76, E-mail address: blf@plen.ku.dk (Brian L. Fredensborg).

15

6

17

8

9




\section{Abstract}

Natural anti-parasitic compounds in plants such as condensed tannins (CT) have anthelmintic properties against a range of gastrointestinal nematodes, but for other helminths such effects are unexplored. The aim of this study was to assess the effects of CT from three different plant extracts in a model system employing the rat tapeworm, Hymenolepis diminuta, in its intermediate host, Tenebrio molitor. An in vitro study examined infectivity of $H$. diminuta cysticercoids (excystation success) isolated from infected beetles exposed to different concentrations of CT extracts from pine bark (PB) (Pinus sps), hazelnut pericarp (HN) (Corylus avellana) or white clover flowers (WC) (Trifolium repens), in comparison with the anthelmintic drug praziquantel (positive control). In the in vitro study, praziquantel and CT from all three plant extracts had dose-dependent inhibitory effects on cysticercoid excystation. The HN extract was most effective at inhibiting excystation, followed by $\mathrm{PB}$ and WC. An in vivo study was carried out on infected beetles (measured as cysticercoid establishment) fed different doses of PB, HN and praziquantel. There was a highly significant inhibitory effect of HN on cysticercoid development $(\mathrm{p}=0.0002)$. Overall, CT showed a promising anticestodal effect against the metacestode stage of $H$. diminuta.

\section{Keywords:}

Condensed tannins, praziquantel, cestodes, invertebrate-parasite model. 


\section{Introduction}

For decades, parasite control in livestock has relied intensively on prophylactic treatment with synthetic anthelmintics, but increasing resistance to such drugs and consumer requests for organic animal products increases the need for alternative control strategies. Bioactive plants may offer potential alternatives for parasite control in vertebrates (Waller and Thamsborg, 2004). Condensed tannins (CT) are a group of secondary metabolites commonly found in tropical and temperate plants (Jansman, 1993). They vary widely in their molecular weights and the identity of the monomeric flavan-3-ol units, which make up the tannin polymers. Procyanidins (PC) consist of catechin or epicatechin, whereas prodelphinidins (PD) are comprised of gallocatechin or epigallocatechin flavan-3-ols (Williams et al., 2014). More complex CT structures may occur as heteropolymers (Mueller-Harvey and McAllan, 1992; Molan et al., 2003). Several laboratory and field experiments have shown that plant CT may control gastrointestinal nematodes (Hoste et al., 2006; Novobilský et al., 2011; Novobilský et al., 2013). Besides anthelminthic properties, these bioactive plant products can also have beneficial effects on animal health and production (Hoskin et al., 2000; RamírezRestrepo et al., 2004; Hoste et al., 2005; Hoste et al., 2006), and reduce the level of host infection (Hoste et al., 2012). Although, in vitro anthelmintic efficacy of natural plant cysteine proteinases has also been reported against excysted scolices and adult worms of the rodent cestodes Hymenolepis diminuta and Hymenolepis microstoma (Mansur et al., 2014), the effect of CT against helminth taxa other than nematodes has not yet been investigated. 
Due to close resemblance of drug effects between animals and humans (Lin, 1995), mammals are often used in pre-clinical pharmacological and toxicological assessment of new compounds (Baumans, 2004). International awareness on animal experimentation has enforced the focus on the "3Rs" to Reduce, Replace and Refine (nc3rs, 2014). An insect model could present an alternative to a range of experimental studies, e.g. as a model for human microbiology (Tan, 2002; Kavanagh and Reeves, 2004) and immunology (Pursall and Rolff, 2011). Further, invertebrate models may simplify and reduce costs of laboratory maintenance (Scully and Bidochka, 2006; Vokrrál et al., 2012) and ease concerns associated with animal experimentation (Kemp and Massey, 2007).

In the present study, a host-parasite model employing the flour beetle Tenebrio molitor (Coleoptera) and the rat tapeworm Hymenolepis diminuta (Cestoda) was used to investigate the anti-cestodal effects of $\mathrm{CT}$ in three different plant extracts. Tenebrio molitor- H. diminuta is a well-known host-parasite model for studies on ecological and evolutionary host-parasite relationships (Shostak, 2014), and Woolsey, (2012) studied its potential for pre-clinical screening of anthelmintics (praziquantel, levamisole hydrochloride and mebendazole).

In the natural lifecycle, rats excrete infective $H$. diminuta eggs which are ingested by the flour beetles where they encyst as larvae (cysticercoid) in the hemocoel (Burt, 1980). The life cycle completes when an infected beetle is eaten by a rat, in which the cysticercoid excysts, attaches to the intestinal wall and develops into an egg producing tapeworm (Chappell et al., 1970). Since the development of egg into cysticercoid and its excystation plays a crucial role in maintaining the life-cycle of $H$. diminuta, 
interruption of these processes with $\mathrm{CT}$ would indicate that CT contains anti-cestodal properties.

The objective of the present study was to assess the anti-cestodal effects of three different $\mathrm{CT}$ types against cysticercoids of $H$. diminuta both freely exposed (in vitro) and within their intermediate host (in vivo), at a range of concentrations.

\section{Materials and Methods}

The in vitro experiments were performed with cysticercoids dissected from experimentally infected beetles. The effect of CT was measured as a reduction of excystation of cysticercoids, which serves as an important measure (proxy) for infectivity to rats. The in vivo study was conducted in live beetles in order to measure the establishment of cysticercoids in the presence of CT.

\subsection{Condensed tannins and praziquantel}

Condensed tannins were extracted and purified from three different plant sources. These were pine bark (PB) (Pinus sp), hazelnut pericarp (HN) (Corylus avellana) and white

of procyanidins (PC) and prodelphinidins (PD), however our previous work has demonstrated that these three plants contain narrower tannin profiles, i.e. mainly PC or PD (Williams et al. 2014). Therefore, we used these plants as a source of well-defined model tannins that would allow us to investigate whether the molecular structure of the tannins influenced possible anti-parasitic activity. Tannins were extracted and analyzed as previously described (Williams et al., 2014). Briefly, $50 \mathrm{~g}$ of plant material was extracted 
with acetone/water $(7: 3 ; \mathrm{v} / \mathrm{v})$ at room temperature, concentrated and freeze-dried. Tannin analysis was carried out by thiolytic degradation of the polymers and subsequent HPLC analysis of the reaction products, providing information on CT content in the extract, the mean degree of polymerization ( $\mathrm{mDP}$, i.e. average CT polymer size) and the $\mathrm{PC}$ )/ $\mathrm{PD}$ ratio (Williams et al., 2014). Pine bark contained $50.8 \mathrm{~g} \mathrm{CT/100} \mathrm{g} \mathrm{extract,} \mathrm{with} \mathrm{an} \mathrm{mDP} \mathrm{value} \mathrm{of}$ 2.5 and a PC/PD ratio of 64.2. Hazelnut pericarp contained $73.8 \mathrm{~g} \mathrm{CT/100} \mathrm{g} \mathrm{extract} \mathrm{with} \mathrm{an}$ mDP value of 9.6 and a PC/PD ratio of 79.5. White clover contained $33.8 \mathrm{~g} \mathrm{CT} / 100 \mathrm{~g}$ extract with an mDP value of 4.4 and, in contrast to the other extracts, its tannins were almost exclusively comprised of PD, i.e. the PC/PD ratio was 0.8/99.2 (Williams et al., 2014). The well-known anti-cestodal drug praziquantel $\left(99.7 \%\right.$, VETRANAL $\left.{ }^{\mathrm{TM}}\right)$ was used as a positive control for both in vitro and in vivo studies.

\subsection{Management of the beetles}

Tenebrio molitor larvae (obtained from Avifauna ApS, Denmark) were propagated in plastic containers $(30 \times 21 \times 20 \mathrm{~cm})$, placed in a dark incubator $\left(26^{\circ} \mathrm{C}\right)$, and provided with fresh oatmeal and fresh slices of potato. The potato slices were changed twice a week. After 2 weeks of incubation, pupae started to develop and these were then transferred into another plastic container $(30 \times 21 \times 20 \mathrm{~cm})$ and kept in a dark incubator $\left(26^{\circ} \mathrm{C}\right)$ until emergence of adults. Newly emerged adults were transferred to new plastic containers $(30 \times 21 \times 20 \mathrm{~cm})$ twice a week and held under the conditions described above. 


\subsection{Infection of beetles}

Feces was collected from $H$. diminuta infected rats (Rattus norvigecus - Wistar strain) stabled at the Veterinary Institute, Technical University of Denmark (Animal permission no. $2010 / 561-1914$-section C10) and stored at $10{ }^{\circ} \mathrm{C}$ until use (two weeks maximum). Ten $\mathrm{g}$ of fecal pellets were soaked $1 \mathrm{~h}$ in $25 \mathrm{ml}$ of tap water and then stirred with a wooden stick to make a uniform paste. The fecal paste was poured through a double layer of cotton gauze $(1 \times 1 \mathrm{~mm}$ pore size $)$ into a $200 \mathrm{ml}$ plastic cup, and the gauze was rinsed thoroughly with approximately $75 \mathrm{ml}$ of tap water to increase egg recovery. The resulting suspension was equally transferred into two $50 \mathrm{ml}$ centrifuge tubes. The tubes were centrifuged (Universal 16R) at $1148 \mathrm{~g}$ for $7 \mathrm{~min}$. The supernatant was removed and the sediment was again stirred with a wooden stick. This fecal paste containing the $H$. diminuta eggs was used to infect the beetles.

Before administration of the paste, a group of 50 beetles were left without feed for $72 \mathrm{~h}$ in plastic containers $(30 \times 21 \times 20 \mathrm{~cm})$ with filter paper at the base, and stored in a dark incubator $\left(26^{\circ} \mathrm{C}\right)$. For infection, a $10 \mu \mathrm{l}$ fecal suspension was deposited on a coverslip $(1.5 \times 1.5 \mathrm{~cm})$ placed on filter paper in a series of petri dishes $(5.5 \mathrm{~cm}$ diameter, $1.42 \mathrm{~cm}$ depth). A starved beetle was placed inside each Petri dish covered by a lid, and placed in a dark room for an hour. For assessment of eventual evaporation of the fecal suspension, one petri dish setup (without a beetle) was left an hour. Only beetles that had consumed the entire $10 \mu \mathrm{l}$ of fecal suspension after $1 \mathrm{~h}$ were considered successfully inoculated and were included in the experiments.

2.4. In vitro study with praziquantel and pine bark extract 
At 15 days post inoculation, beetles were dissected and cysticercoids were recovered using a Pasteur pipette under a dissection microscope (40x). A maximum of 10 cysticercoids (first observed) from each beetle were transferred to a watch-glass (33 $\mathrm{mm}$ diameter, $7 \mathrm{~mm}$ deep) containing phosphate buffered saline (PBS) and a total of 80 cysticercoids were collected. From these, 10 cysticercoids (first observed) were placed in each of 8 wells ( 2 wells from 4 different 48 multi-well plastic plates). Then each well was treated with $150 \mu \mathrm{l}$ of either praziquantel dissolved in $2 \%$ dimethyl sulfoxide (DMSO) with a final concentration of $10^{-2}$ (high concentration), $10^{-3}$ (medium concentration) or $10^{-4} \mathrm{mg} / \mathrm{ml}$ (low concentration), or CT extracts from PB dissolved in Milli-Q ${ }^{\mathrm{TM}}$ water at a final concentration of $0.1,0.5$ or $2.5 \mathrm{mg} \mathrm{CT} / \mathrm{ml}$. Control consisted of $2 \%$ DMSO or Milli- $\mathrm{Q}^{\mathrm{TM}}$ water. All plates were subsequently kept in an incubator at $37^{\circ} \mathrm{C}$ for $1 \mathrm{~h}$.

After $1 \mathrm{~h}$ of incubation, the 10 cysticercoids along with the respective treatment solution from each well were transferred separately to a watch glass and the treatment solution was then removed with a Pasture pipette under a dissection microscope. One $\mathrm{ml}$ of $\mathrm{HCl}$-pepsin solution [2 $\mathrm{ml} 37 \% \mathrm{HCl}, 20 \mathrm{ml}$ warm $0.9 \%$ saline, $0.8 \mathrm{~g}$ pepsin powder from porcine gastric mucosa (1:2500, Sigma Life Science)] was added and placed in an incubator $\left(37^{\circ} \mathrm{C}\right)$. After 10 min of incubation, all the $\mathrm{HCl}$-pepsin solution was removed. The cysticercoids were washed three times with $1 \mathrm{ml}$ warm $\left(37^{\circ} \mathrm{C}\right) \mathrm{PBS}$ and $1 \mathrm{ml}$ of trypsin-taurocholate solution [0.1 g sodium taurocholate hydrate powder, $0.1 \mathrm{~g}$ trypsin powder from porcine pancreas, (97\%, Sigma Life Science), $10 \mathrm{ml}$ warm PBS] was added to the watch glass and placed in the incubator at $37{ }^{\circ} \mathrm{C}$ for $2.5 \mathrm{~h}$. The cysticercoids were then observed under the dissection microscope (40x) and recorded 
as excystated (complete evagination and emergence of scolex and body part from the cyst) or non excystated (absence of the above) (Roberts and Janovy, 2008). This experiment was repeated five times. contained equal final concentrations of CT in the assay. Three different concentrations: 2.5 (high concentration), 0.25 (medium concentration) and $0.025 \mathrm{mg} \mathrm{CT} / \mathrm{ml}$ (low concentration) in Milli- $\mathrm{Q}^{\mathrm{TM}}$ water from each were prepared. Pure Milli- $\mathrm{Q}^{\mathrm{TM}}$ water was used as a control. The procedure was as described above (see: In vitro study of praziquantel and $\mathrm{PB}$ ) and was repeated five times.

As the CT extracts used in this experiment were not $100 \%$ pure, CT depletion experiments were performed, to investigate whether inhibition of cysticercoid excystation was exclusively due to the effect of CT. A total volume of $250 \mu$ l solution with concentration $2.5 \mathrm{mg} \mathrm{CT} / \mathrm{ml}$ of Milli- $\mathrm{Q}^{\mathrm{TM}}$ water was prepared separately from three types of CT extracts (PB, HN, and WC). For each solution, $12.5 \mathrm{mg}$ of polyvinylpolypyrrolidone (PVPP) (at a dose rate of $50 \mathrm{mg} \mathrm{PVPP} / \mathrm{ml}$ of solution) was added to precipitate CT, and was incubated $\left(4^{\circ} \mathrm{C}\right)$ overnight. After centrifugation at $3000 \mathrm{~g}$ for $5 \mathrm{~min}$, supernatant (CT depleted extract) was removed and used in the test 
$\left(4^{\circ} \mathrm{C}\right)$ overnight. The above procedure (see: In vitro study of praziquantel and $\mathrm{PB}$ ) was then followed and was repeated three times.

2.7. In vivo study with praziquantel, pine bark and hazelnut extracts

Eighty uninfected beetles (7- 14 days after eclosion) were randomly selected and depleted feed for $72 \mathrm{~h}$ as described above. Starved beetles were then randomly allocated into 8 groups, each with 10 beetles. The beetles of each group were presented individually to a droplet of $5 \mu 1$ containing one of the following treatments: praziquantel $(25,50$ and $100 \mathrm{mg} / \mathrm{kg}$ body weight of beetle), or PB (125, 250 and 500 mg CT/kg body weight of beetle), or $2 \% \mathrm{DMSO}$, or Milli- $\mathrm{Q}^{\mathrm{TM}}$ water for $15 \mathrm{~min}$. Doses were formulated by measuring the average weight $(+\mathrm{SE})$ of the beetles $(103 \pm 4.4 \mathrm{mg})$, which was calculated by weighing randomly allocated 25 beetles in 6 different groups. maintained individually as described earlier (see: In vitro study).

After 15 days of incubation, 4 beetles were selected randomly from each treatment group for quantification of the establishment of cysticercoids. All cysticercoids in the haemocoel of the beetle were counted and recorded. The experiment for praziquantel and PB was repeated five and three times, respectively.

A separate study tested the effects of $\mathrm{HN}$ on cysticercoid establishment. A single dose of $\mathrm{HN}$ (500 $\mathrm{mg} \mathrm{CT} / \mathrm{kg}$ body weight) or a control (Milli- $\mathrm{Q}^{\mathrm{TM}}$ water) were fed to infected beetles and all the procedures were done as described above, and was repeated three times. 
All statistical analyses were performed using $\mathrm{SAS}^{\circledR}$ version 9.3 (SAS institute Inc, Cary, North Carolina). Data from the in vitro study (except the CT depletion assay) fulfilled all three assumptions of ANOVA. So, the proportions of cysticercoid excystation in treatment groups were analyzed using PROC GLM fitting repetitions of experiments as a random variable. When an overall significant effect was seen, pairwise comparisons were done using a post-hoc Tukey test. The data from the CT depletion assay were analyzed by using a non-parametric Wilcoxon rank sum test. In the in vivo study, the numbers of cysticercoids established in the treatment groups were analyzed using PROC GENMOD, fitting negative binomial distributions. When overall differences were observed individual comparisons were done using least square means.

\section{Results}

3.1. In vitro study with praziquantel and pine bark extract

All concentrations of praziquantel and PB significantly reduced the mean percentage of cysticercoid excystation compared to their respective controls (Figs. 1A \& B) and a significant concentration dependent effect was observed for both treatments with the highest concentrations having the strongest inhibitory effect on excystation $\left(F_{2,4}=26.87, p=0.0003\right.$ for praziquantel and $F_{2,4}=25.57, p=0.0003$ for PB $)$. The cysticercoid excystation inhibitory effect was the same for the praziquantel and PB treatments $\left(\mathrm{F}_{1,4}=0.49, \mathrm{p}=0.4887\right)$. 

were significantly different among the treatment groups $\left(\mathrm{F}_{3,4}=28.37, \mathrm{p}<0.0001\right)$ and concentrations $\left(\mathrm{F}_{2,4}=110.58, \mathrm{p}<0.0001\right.$; Fig. 2$)$ and there was an interaction between treatment groups and concentrations $\left(\mathrm{F}_{4,4}=5.48, \mathrm{p}=0.0015\right)$. Concentration was found to be a significant parameter for all three CT with the highest concentrations having the strongest negative effect on excystation $\left(\mathrm{F}_{2,4}=66.48, \mathrm{p}<0.0001\right.$ for $\mathrm{PB}, \mathrm{F}_{2,4}=9.97, \mathrm{p}=$ 0.0067 for $\mathrm{HN}$ and WC).

The mean percentage of cysticercoid excystation with all three CT depleted solutions showed significantly more cysticercoid excystation compared to their respective controls $\left(\chi^{2}=4.09, \mathrm{df}=1, \mathrm{p}=0.043\right.$ for $\mathrm{PB}$ and $\mathrm{WC}, \chi^{2}=3.97, \mathrm{df}=1, \mathrm{p}=$ 0.043 for HN; Fig. 3).

\subsection{In vivo study with praziquantel, pine bark and hazelnut extracts}

There was a significant effect of treatment (praziquantel and PB) on cysticercoid establishment $\left(\chi^{2}=133.1, \mathrm{df}=3, \mathrm{p}<0.0001\right)$ but the effect was not dose dependent $\left(\chi^{2}\right.$ $=1.92, \mathrm{df}=2, \mathrm{p}=0.382$ ). All three doses of praziquantel reduced cysticercoid establishment to almost zero while each beetle in the control treatment had + SE $27.1 \pm$ 6.65 cysticercoids (Fig. 4A), whereas the effect of CT from PB at all doses did not differ from the control, although there was a trend of reduced establishment $(p=0.841$, 0.374 and 0.098 for low, medium and high doses respectively; Fig. 4B).

The separate experiment with $\mathrm{HN}$ at $500 \mathrm{mg} \mathrm{CT} / \mathrm{kg}$ beetle body weight revealed significantly lower cysticercoid establishment (mean cysticercoids per beetle + SE: 25.5 

\pm 2.54 ) in comparison to the control group (mean cysticercoids per beetle + SE: $36.3 \pm$ 2.33), $\left(\chi^{2}=10.48, \mathrm{df}=1, \mathrm{p}=0.0012\right)$.

\section{Discussion}

The results from the in vitro study suggest that treatment with CT from three different plants $(\mathrm{PB}, \mathrm{HN}$ and $\mathrm{WC})$ and praziquantel can substantially reduce the excystation of $H$. diminuta cysticercoids in a concentration-dependent manner. A similar concentration-dependent inhibitory effect of praziquantel has been previously shown using the same model (Woolsey, 2012). Our in vivo results showed that PB did not significantly inhibit cysticercoid establishment, but praziquantel and $\mathrm{HN}$ were associated with a reduction in the number of established cysticercoids. The cysticercoid excystation inhibitory effect of CT from the three plant extracts disappeared in the presence of tannin-inhibitor polyvinylpolypyrrolidone (PVPP)(Hagerman and Butler, 1981), confirming that $\mathrm{CT}$ are the major active compounds for the observed inhibition. The observed effects of $\mathrm{CT}$ in this model are most likely due to their direct antiparasitic activity, although additional, indirect effects by increasing host resistance may occur in mammals (Hoste et al., 2006).

The cysticercoid capsule, scolex and other cellular structures contain protein with polysaccharides and lipids (Burt, 1980). As CT are able to bind to proteins (Hoste et al., 2006), they might interact with the protein portion of the cystic capsule and alter its physical and chemical properties, as reported previously for Trichostrongylus colubriformis, where direct damage to the cuticle was observed after incubation with CT (Hoste et al., 2006). Condensed tannins might also interfere with enzyme activities, 
which are involved in metabolic pathways responsible for the development and functioning of parasites (Athanasiadou et al., 2001). Furthermore, due to the presence of pores and vesicles in the cystic capsule (Burt, 1980), bioactive compounds may reach the internal structures of the scolex and other cellular proteins. Taken together, all of these changes might interfere with the cysticercoid structures and metabolic pathways, which are essential in cysticercoid functioning and excystation. However, the exact mode of action of $\mathrm{CT}$ and the active compounds responsible for the anthelmintic activity are still unknown (Novobilský et al., 2013) and could differ depending on the species of parasite, its developmental stage, and possibly the biochemical characters and structures of the forage species (Min and Hart, 2003).

The different potency of CT from these plant extracts may be associated with the percentage of procyanidin monomer units or the $\mathrm{mDP}$ of the CT polymer, as the CT content in all three applied samples was standardized in the assays. However, HN also contains a small percentage of galloylated CTs (Irene Mueller-Harvey and Christos 
the insect gut. Anthelminthic activities of CT from different plants or plant extracts are known to have markedly different effects on parasites. For example, grazing of sheep on Lotus pendunculatus reduced nematode fecal egg counts more effectively than grazing on L. corniculatus (Niezen et al., 1998), as L. pedunculatus has a higher PD/ PC ratio than $L$. corniculatus (Foo et al., 1997). Thus, the multitude of different CT structures (Mueller-Harvey and McAllan, 1992) may influence their biological activities (Athanasiadou et al., 2001). Further experiments are needed to determine the relative contributions of $\mathrm{mDP}$ and $\mathrm{PD} / \mathrm{PC}$ ratio on cysticercoid excystation.

Availability of free $\mathrm{CT}$ in the intestine may be important factor for $\mathrm{CT}$ to be effective. Formation and dissociation of the protein-CT complex is highly $\mathrm{pH}$ dependent. Stable protein-CT complexes are formed at $\mathrm{pH} 5-7$, but the complexes easily dissociate and release proteins at higher and lower $\mathrm{pH}$ (Mueller-Harvey and McAllan, 1992). Optimum complex formation occurs at the isoelectric point of the protein, but little is known about the isoelectric point of proteins in the beetle gut. There 
a first screening of potentially interesting compounds. This invertebrate model has several advantages over vertebrate models as far as, ethical clearance, legislation, time and cost are concerned. Future studies will need to address the mechanism of CT action and include comparative studies with vertebrate animals in order to explore their effects against the different lifecycle stages and species of tapeworms.

\section{Acknowledgements}

Authors wish to thank Mrs Sheeva Bhattarai for critically reading the manuscript. We would also like to acknowledge Azmi Aljubury, Fredrik Horton Samuelsson, Louise Lee Munk Larsen and Charlotte Fischer for their help in the laboratory. We acknowledge financial support from the European Commission (Marie Curie Initial Training Network, PITN-GA-2011-289377, “LegumePlus”). ARW was supported by the Danish Council for Independent Research (Technology and Production Sciences Grant \# 12-126630).

\section{References}

Athanasiadou, S., Kyriazakis, I., Jackson, F., Coop, R.L., 2001. Direct anthelmintic effects of condensed tannins towards different gastrointestinal nematodes of sheep: in vitro and in vivo studies. Vet. Parasitol. 99, 205-219. Ther. 11, S64-S66. 
Brunet, S., Hoste, H., 2006. Monomers of condensed tannins affect the larval exsheathment of parasitic nematodes of ruminants. J. Agri. Food Chem. 54, 74817487.

Burt, M. D. B. 1980. Aspects of the life history and systematics of Hymenolepis diminuta. In: Arai, H. P. (Ed.), Biology of the Tapeworm Hymenolepis diminuta. Academic press, New York, pp.1-57.

Chappell, L.H., Arai, H.P., Dike, S.C., Read, C.P., 1970. Circadian migration of Hymenolepis (Cestoda) in the intestine-I. Observations on H. diminuta in the rat. Comp. Biochem. Physiol. 34, 31-46.

Foo, L.Y., Lu, Y., McNabb, W.C., Waghorn, G., Ulyatt, M.J., 1997. Proanthocyanidins 350 from Lotus pedunculatus. Phytochemistry. 45, 1689-1696.

Gullan, P. J., Cranston, P. S., 2010. The insects: An outline of Entomology. Wileyblackwell, UK, pp.79.

Hagerman, A. E., Butler, L. G., 1981. The specificity of proanthocyanidin-protein interactions. J. Biol. Chem. 266, 4494-4497. of sainfoin hay on gastrointestinal parasitism with nematodes and milk production 
Hoste, H., Jackson, F., Athanasiadou, S., Thamsborg, S.M., Hoskin, S.O., 2006. The effects of tannin-rich plants on parasitic nematodes in ruminants. Trends Parasitol. $22,253-261$.

Hoste, H., Martinez-Ortiz-De-Montellano, C., Manolaraki, F., Brunet, S., OjedaRobertos, N., Fourquaux, I., Torres-Acosta, J.F.J., Sandoval-Castro, C.A., 2012. Direct and indirect effects of bioactive tannin-rich tropical and temperate legumes against nematode infections. Vet. Parasitol. 186, 18-27.

Jansman, A. J. M., 1993. Tannins in feedstuffs for simple-stomached animals. Nutr. Res. Rev. 6, 209-236.

Lin, J. H. 1995. Species similarities and differences in pharmacokinetics. Drug Metab. Dispos. 23, 1008-1021.

Kavanagh, K., Reeves, E.P., 2004. Exploiting the potential of insects for in vivo pathogenicity testing of microbial pathogens. FEMS Microbiol. Rev. 28, 101-112.

Kemp, M.W., Massey, R.C., 2007. The use of insect models to study human pathogens.

Mansur, F., Luoga, W., Buttle, D.J., Duce, I.R., Lowe, A., Behnke, J.M., 2014. The anthelmintic efficacy of natural plant cysteine proteinases against two rodent cestodes Hymenolepis diminuta and Hymenolepis microstoma in vitro. Vet. Parasitol. 201, 48-58.

Min, B.R., Hart, S.P., 2003. Tannins for suppression of internal parasites. J. Anim. Sci. 81, E102-E109. 
Molan, A. L., Meagher, L. P., Spencer, P. A., Sivakumaran, S., 2003. Effect of flavan3-ols on in vitro egg hatching, larval development and viability of infective larvae of Trichostrongylus colubriformis. Int. J. Parasitol. 33, 1691-1698.

Mueller-Harvey, I., McAllan, A.B., 1992. Tannins: their biochemistry and nutritional properties. Adv. Plant Cell Biochem. Biotechnol. 1, 151-217.

nc3rs, 2014. http://www.nc3rs.org.uk/page.asp?id=7, accessed on July $7^{\text {th }} 2014$.

Niezen, J.H., Robertson, H.A., Waghorn, G.C., Charleston, W.A.G., 1998. Production, faecal egg counts and worm burdens of ewe lambs which grazed six contrasting forages. Vet. Parasitol. 80, 15-27.

Novobilský, A., Mueller-Harvey, I., Thamsborg, S.M., 2011. Condensed tannins act against cattle nematodes. Vet. Parasitol. 182, 213-220.

Novobilský, A., Stringano, E., Hayot Carbonero, C., Smith, L.M.J., Enemark, H.L., Mueller-Harvey, I., Thamsborg, S.M., 2013. In vitro effects of extracts and purified tannins of sainfoin (Onobrychis viciifolia) against two cattle nematodes. Vet. Parasitol. 196, 532-537.

Pursall, E.R., Rolff, J., 2011. Immune responses accelerate ageing: proof-of-principle in an insect model. PLoS ONE 6, 1-7.

Ramírez-Restrepo, C.A., Barry, T.N., López-Villalobos, N., Kemp, P.D., McNabb, W.C., 2004. Use of Lotus corniculatus containing condensed tannins to increase lamb and wool production under commercial dryland farming conditions without the use of anthelmintics. Anim. Feed Sci. Technol. 117, 85-105.

Roberts, L. S., Janovy, J., 2008. Gerald D. Schmidt \& Larry S. Roberts' Foundations of Parasitology. McGraw-Hill, New York, pp.313-363. 
Scully, L.R., Bidochka, M.J., 2006. Developing insect models for the study of current and emerging human pathogens. FEMS Microbiol. Lett. 263, 1-9.

Shostak, A.W., 2014. Hymenolepis diminuta infections in Tenebrionid beetles as a 409 model system for ecological interactions between helminth parasites and terrestrial intermediate hosts: A review and meta-analysis. J. Parasitol. 100, 46-58.

Tan, M.-W., 2002. Cross-species infections and their analysis. Annu. Rev. Microbiol. $56,539$.

Vokřál, I., Jirásko, R., Jedličková, V., Bártíková, H., Skálová, L., Lamka, J., Holčapek, M., Szotáková, B., 2012. The inability of tapeworm Hymenolepis diminuta and fluke Dicrocoelium dendriticum to metabolize praziquantel. Vet. Parasitol. 185, $168-174$.

Waller, P.J., Thamsborg, S.M., 2004. Nematode control in 'green' ruminant production systems. Trends Parasitol. 20, 493-497.

Williams, A.R., Fryganas, C., Ramsay, A., Mueller-Harvey, I., Thamsborg, S.M., 2014. Direct anthelmintic effects of condensed tannins from diverse plant sources against Ascaris suum. PLoS ONE 9, e97053.

Woolsey, I., 2012. Assessment of pharmaceutical efficacy in the Tenebrio molitor (Coleoptera) - Hymenolepis diminuta (Cestoda) invertebrate-parasite model. MSc.

425 
Fig. 1. In vitro mean percentage $(n=5, \pm S E M)$ of cysticercoids excystation treated with praziquantel (A) and condensed tannin (CT) extract from pine bark (B) at different concentrations. Ten cysticercoids were used for each concentration. Control refers to $2 \%$ DMSO for (A) and to Milli- $\mathrm{Q}^{\mathrm{TM}}$ water for (B). Different letters within each figure represent statistical significance $(\alpha=0.05)$.

Fig. 2. In vitro mean percentage $(n=5, \pm S E M)$ of cysticercoids excystation treated with three different condensed tannin (CT) extracts [white clover flower (WC), pine bark (PB), and hazelnut skin (HN)] at different concentrations. Ten cysticercoids were used

Fig. 3. In vitro mean percentage $(n=3, \pm S E M)$ of cysticercoid excystation treated with three different condensed tannin (CT) depleted solutions (depleted) and condensed tannin extract solutions (control) at $2.5 \mathrm{mg} \mathrm{CT} / \mathrm{ml}$ concentration. Ten cysticercoids were used for each solution of white clover flower (WC), pine bark (PB) and hazelnut pericarp $(\mathrm{HN})$. *refers to a significant difference relative to the respective controls.

Fig. 4. In vivo mean number of cysticercoids ( $\mathrm{n}=5$ for $\mathrm{A}$ and $\mathrm{n}=3$ for $\mathrm{B}, \pm \mathrm{SEM})$ treated with praziquantel (A), and a condensed tannin (CT) extract from pine tree bark (B) at different concentrations. Average numbers of cysticercoids from four beetles were used for each treatment. Control refers to $2 \% \mathrm{DMSO}$ in (A) and to Milli-Q ${ }^{\mathrm{TM}}$ water in (B). 
Fig. 1.

451

A. Praziquantel

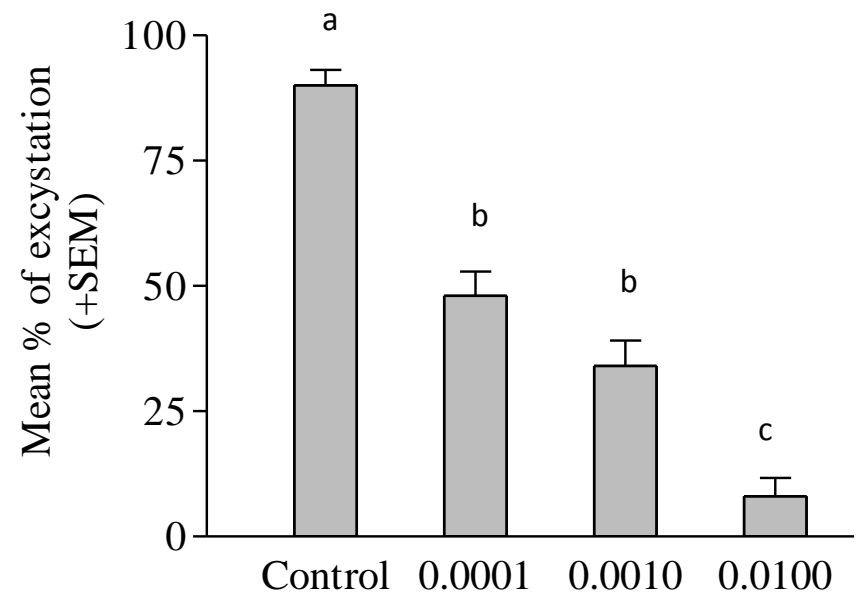

452

Concentration (mg praziquantel/ml)

453 B. Pine tree bark (PB)

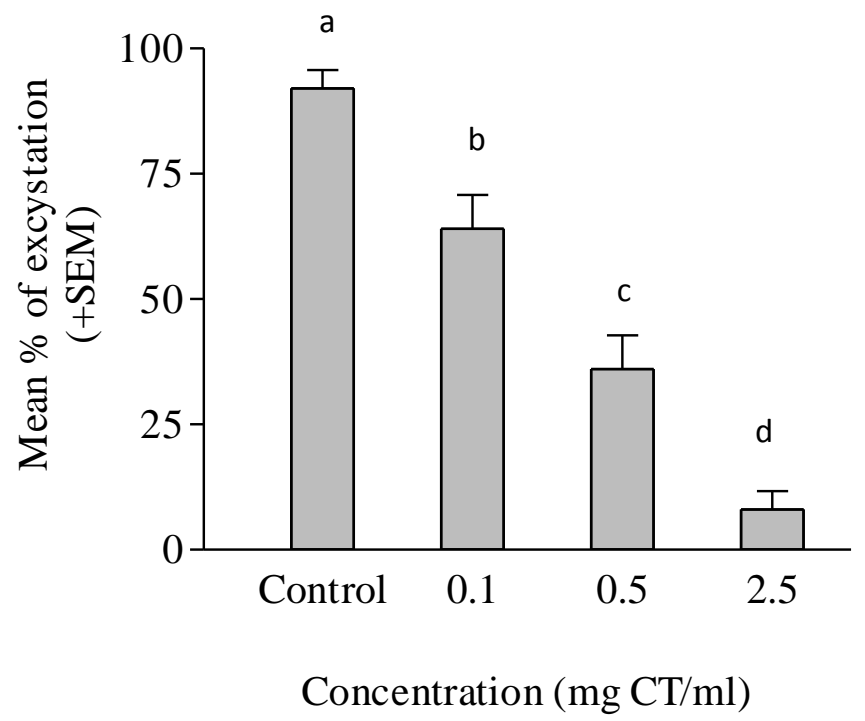


Fig. 2.

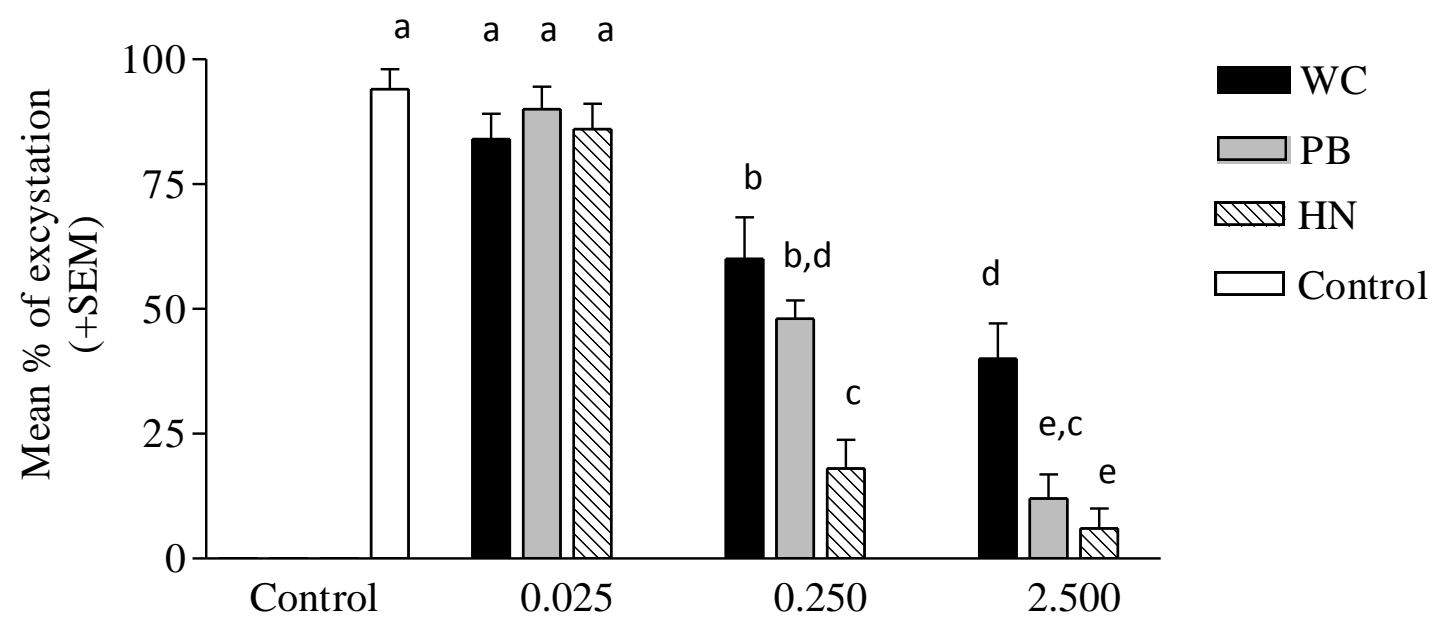

Fig. 3.

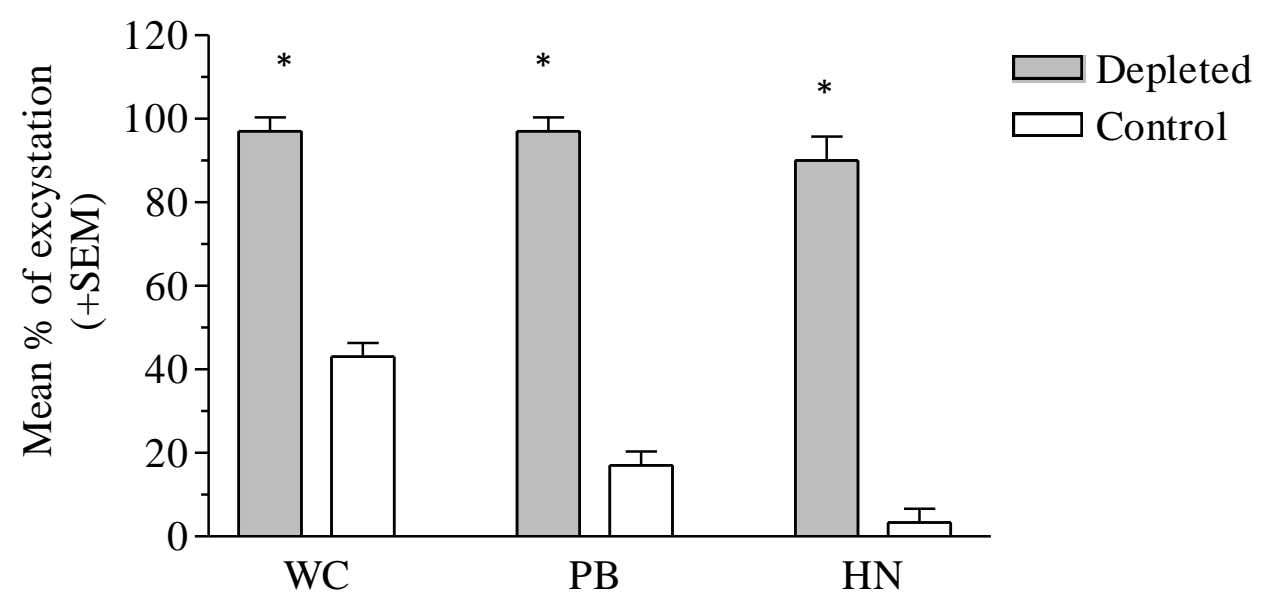

Condensed tannins 
Fig. 4.

463

A. Praziquantel

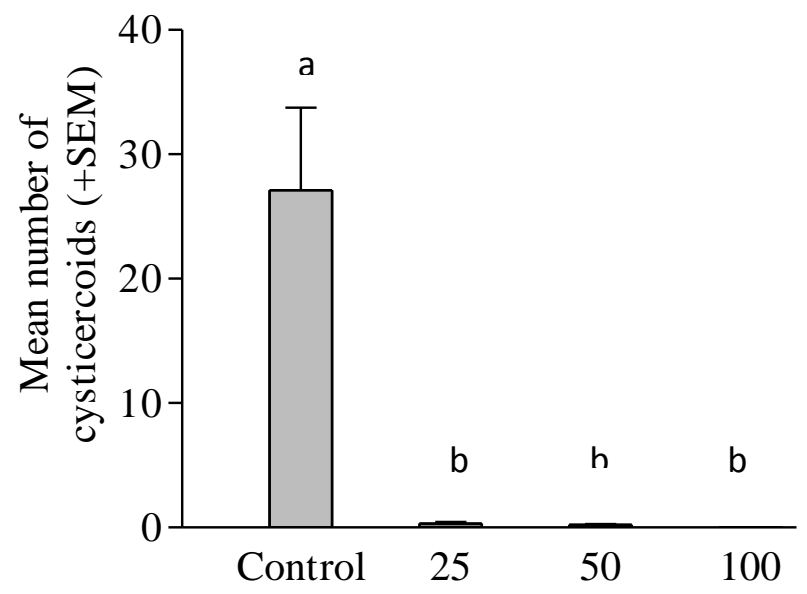

Concentration (mg praziquantel/kg of beetle body weight)

464

465

B. Pine tree bark (PB)

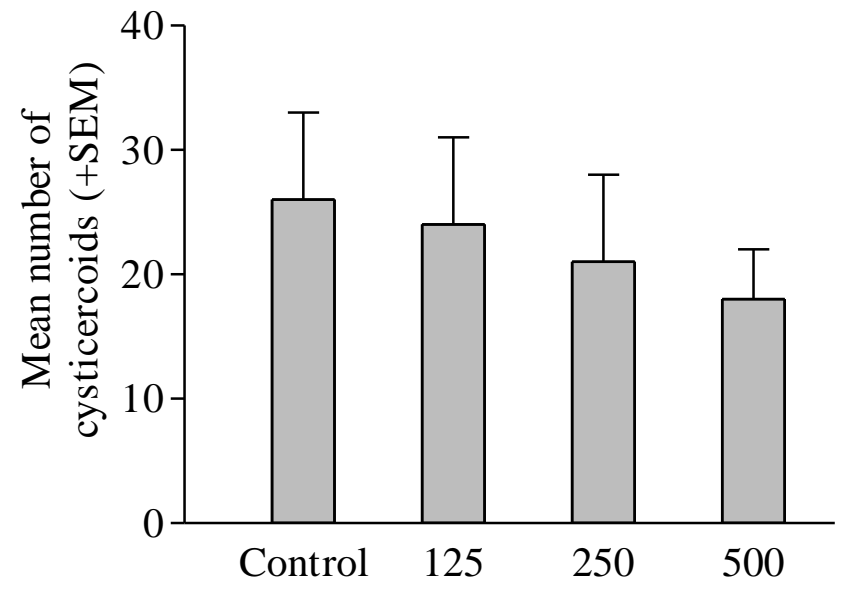

Concentration (mg CT/kg of beetle body weight) 